\title{
Clinical Significance of Amyloid Precursor Protein in Patients with Testicular Germ Cell Tumor
}

\author{
Yuta Yamada, ${ }^{1,2}$ Tetsuya Fujimura, ${ }^{1}$ Satoru Takahashi, ${ }^{3}$ \\ Kenichi Takayama, ${ }^{4,5}$ Tomohiko Urano, ${ }^{4,5}$ Taro Murata, ${ }^{1}$ Daisuke Obinata, ${ }^{3}$ \\ Yasuyoshi Ouchi, ${ }^{4}$ Yukio Homma, ${ }^{1}$ and Satoshi Inoue ${ }^{4,5,6}$ \\ ${ }^{1}$ Department of Urology, Graduate School of Medicine, The University of Tokyo, 7-3-1 Hongo, Bunkyo-ku, Tokyo 113-8655, Japan \\ ${ }^{2}$ Department of Urology, National Center of Global Health and Medicine, Shinjuku-ku, Tokyo, Japan \\ ${ }^{3}$ Department of Urology, Nihon University, School of Medicine, Itabashi-ku, Tokyo, Japan \\ ${ }^{4}$ Department of Geriatric Medicine, Graduate School of Medicine, The University of Tokyo, 7-3-1 Hongo, Bunkyo-ku, \\ Tokyo 113-8655, Japan \\ ${ }^{5}$ Department of Anti-Aging Medicine, Graduate School of Medicine, The University of Tokyo, 7-3-1 Hongo, Bunkyo-ku, \\ Tokyo 113-8655, Japan \\ ${ }^{6}$ Division of Gene Regulation and Signal Transduction, Research Center for Genomic Medicine, Hidaka-shi, Saitama, Japan
}

Correspondence should be addressed to Tetsuya Fujimura; fujimurat-uro@h.u-tokyo.ac.jp

Received 13 February 2013; Accepted 17 March 2013

Academic Editor: Maxwell V. Meng

Copyright (C) 2013 Yuta Yamada et al. This is an open access article distributed under the Creative Commons Attribution License, which permits unrestricted use, distribution, and reproduction in any medium, provided the original work is properly cited.

Introduction. The biological role of amyloid precursor protein (APP) is not well understood, especially in testicular germ cell tumors (TGCTs). Therefore, we aimed to investigate the immunoreactivity (IR) and expression of APP in TGCTs and evaluated its clinical relevance. Materials and Methods. We performed an analysis of immunohistochemistry and mRNA expression of APP in 64 testicular specimens and 21 snap-frozen samples obtained from 1985 to 2004 . We then evaluated the association between APP expression and clinicopathological status in TGCTs. Results. Positive APP IR was observed in 9.8\% (4/41) of seminomatous germ cell tumors (SGCTs) and 39.1\% (9/23) of nonseminomatous germ cell tumors (NGCTs). NGCTs showed significantly more cases of positive IR $(P=0.00870)$ and a higher mRNA expression level compared with those of SGCTs $(P=0.0140)$. Positive APP IR was also significantly associated with $\alpha$-fetoprotein $(\alpha \mathrm{FP})$ elevation $(P=0.00870)$ and venous invasion $(P=0.0414)$. Conclusion. We observed an elevated APP expression in TGCTs, especially in NGCTs. APP may be associated with a more aggressive cancer in TGCTs.

\section{Introduction}

Testicular cancer is a relatively rare cancer that accounts for approximately $1-1.5 \%$ of male cancers, and $90-95 \%$ of these cancers are testicular germ cell tumors (TGCTs) [1]. TGCTs can be classified into two major histological categories, namely, seminomatous germ cell tumor (SGCT) and nonseminomatous germ cell tumor (NGCT). NGCTs, which include yolk sac tumors, embryonal cell carcinomas, teratomas, and choriocarcinomas, are different from SGCTs with regard to clinical characteristics and therapy required.

Amyloid precursor protein (APP) is a type 1 transmembrane protein that is considered to play a key role in Alzheimer's disease. It has multiple isoforms attributable to alternative splicing and is expressed in various types of human cells. APP695 predominantly exists in the neurons whereas other isoforms such as the APP751 and APP770 are expressed in nonneuronal cells [2]. The biological role of APP is not well understood. APP and its cleaved forms have been suggested to mediate various functions, including cell adhesion [3], cell signaling [4], and cell growth [5-7]. These functions are important in carcinogenesis, and APP expression may be involved in the development of various cancers [8-13].

We have previously shown that APP is a primary androgen-responsive gene that promotes the growth of 
prostate cancer cells [14]. In the present study, we investigated APP immunoreactivity (IR) and APP mRNA expression in TGCTs and evaluated its clinical significance.

\section{Materials and Methods}

2.1. Patient Characteristics and Tissue Preparation. Sixty-four testicular specimens and 21 snap-frozen testicular samples were obtained from orchiectomies performed between 1985 and 2004. These samples were used for analysis of APP immunostaining and mRNA expression.

For APP immunostaining, 64 cancerous lesions and 31 benign testicular lesions were identified in 64 slides. The 64 cancerous lesions included 41 SGCTs and 23 NGCTs. NGCT lesions consisted of 3 embryonal carcinomas, 1 teratoma, 1 yolk sac tumor, and 18 mixed germ cell tumors (no case of pure choriocarcinoma). Of the 18 mixed TGCTs, 10 TGCTs consisted of both SGCT and other components of NGCT. Staging was performed according to the TNM 2009 staging system [1]. Patients with metastasis (12 cases) were also classified in terms of prognosis according to the International Germ Cell Consensus Classification (IGCCC) [15].

The age of the patients ranged from 0 to 71 years (mean, 35.2 years). Forty-two patients had pathological stage T1, and 22 patients had T2-T4. Mean levels of lactate dehydrogenase $(\mathrm{LDH})$, beta human chorionic gonadotropin $(\beta \mathrm{hCG})$, and $\alpha$-fetoprotein $(\alpha \mathrm{FP})$ were $363 \mathrm{IU} / \mathrm{mL}, 614 \mathrm{ng} / \mathrm{mL}$, and $431 \mathrm{ng} / \mathrm{mL}$, respectively. Before surgery, no patients received chemotherapy or radiation. This study was approved by our institutional ethical committee. All the patients or their parents provided a written informed consent.

2.2. Immunohistochemistry. Immunohistochemistry for APP expression was performed by the streptavidin-biotin method as previously described [16]. Six-micrometer-thick sections were deparaffinized with 2 changes of xylene for 3 min each, then dehydrated using decreasing concentrations of ethanol, and rinsed in Tris-buffered saline (TBS). Antigen retrieval was carried out immersing the sections in citric acid buffer ( $2 \mathrm{mM}$ citric acid and $9 \mathrm{mM}$ trisodium citrate dehydrate, $\mathrm{pH}$ 6.0) and autoclaved at $121^{\circ} \mathrm{C}$ for $10 \mathrm{~min}$. After a cooling period of $3 \mathrm{~min}$, the sections were washed with TBS and blocked with endogenous peroxidase with $0.3 \% \mathrm{H}_{2} \mathrm{O}_{2}$. The sections were then incubated in $10 \%$ bovine serum albumin (BSA) for $30 \mathrm{~min}$. The slides were incubated overnight at $4^{\circ} \mathrm{C}$ with a primary rabbit polyclonal antibody for APP. For primary antibody, we applied 1:100 diluted rabbit polyclonal antibody for APP (number 2452, Cell Signaling Technology, Tokyo, Japan). After the sections were washed in TBS, they were incubated with Envision (DAKO, Carpinteria, CA, USA). The antigen-antibody complex was visualized with $3,3^{\prime}$-diaminobenzidine tetrachloride (DAB) solution (1 mM $\mathrm{DAB}, 50 \mathrm{mM}$ Tris- $\mathrm{HCl}$ buffer, $\mathrm{pH} 7.6$, and $0.006 \% \mathrm{H}_{2} \mathrm{O}_{2}$ ). For negative controls, normal rabbit IgG was used instead of primary antibodies.

2.3. Antibodies. Anti-APP antibody is a rabbit polyclonal antibody produced by immunizing rabbits with a synthetic peptide corresponding to residues surrounding the Thr668 of human APP695. Antibodies used in this study detect endogeneous levels of several isoforms of $\beta$ amyloid precursor protein including APP695, APP770, and APP751 (number 2452, Cell Signaling Technology, Tokyo, Japan).

2.4. Immunohistochemical Assessment. Immunostained slides were evaluated for intensity scores as described in the previous literature [17]. The intensity score of immunostaining was rated from 0 to $3+$ (0: none, 1: weak, 2: moderate, 3: strong), with $2+$ or $3+$ staining considered "positive immunoreactivity (IR)" for protein overexpression. A score of $1+$ was considered the cut-off point because all normal testicular lesions showed an intensity score of 0 to $1+$. Two observers (Y. Yamada and T. Fujimura) evaluated the slides, and a third observer ( $T$. Murata) estimated the scores of the slides in case of disagreement between the 2 observers.

2.5. RNA Extraction and Quantitative Reverse TranscriptionPolymerase Chain Reaction. Total RNA was extracted from snap-frozen samples using ISOGEN reagent (Nippon Gene, Tokyo, Japan). First-strand cDNA was generated using PrimeScript (Takara, Kyoto, Japan). The resulting cDNA was subjected to real-time polymerase chain reaction (PCR) using an Applied Biosystems 7000 sequence detector system based on SYBR Green I fluorescence. mRNA expression was normalized for GAPDH mRNA levels. PCR protocol was as previously described [18]. Sequences of PCR primers are described below.

GAPDH forward: GGTGGTCTCCTCTGACTTCAACA

GAPDH reverse: GTGGTCGTTGAGGGCAATG

APP forward: CACAGAGAGAACCACCAGCA

APP reverse: ACATCCGCCGTAAAAGAATG.

2.6. Statistical Analyses. We used the statistical software JMP Pro version 9.0.2 (2010 SAS Institute Inc.) for data analysis. The chi-square test $\left(\chi^{2}\right)$ and Fisher test were used for analysis of association between APP IR and clinicopathological characteristics such as tumor stage; lymph node stage; clinical stage; pretreatment serum levels of $\mathrm{LDH}, \alpha \mathrm{FP}$, and $\beta \mathrm{hCG}$; and prognostic classification (IGCCC 1997). Students' $t$-test and Welch test were used for the evaluation of APP level in compared histological groups. Mann-Whitney $U$ test was used to analyze statistical differences in the relative levels of APP mRNA between SGCTs and NGCTs. Log-rank test was performed to analyze the statistical difference of cancerspecific survival between patients with a SGCT and those with an NGCT. A $P$ value of $<0.05$ was considered statistically significant.

\section{Results}

3.1. APP Immunostaining in Normal Testicular Tissue and Testicular Germ Cell Tumor. Majority of the patients with benign testicular lesion (80.6\%) and SGCT (87.8\%) had no 


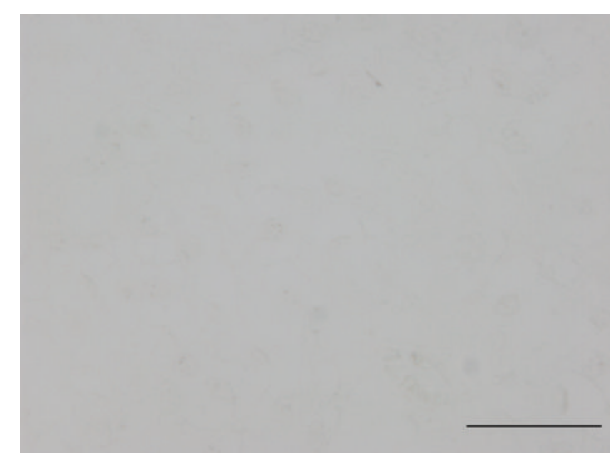

(a) Negative control

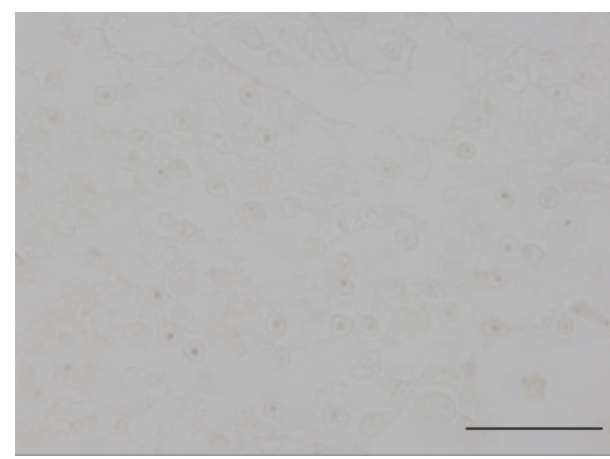

(c) SGCT

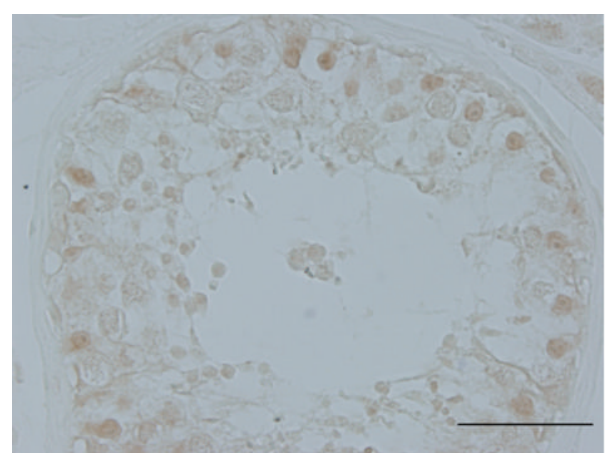

(b) Normal testicular lesion

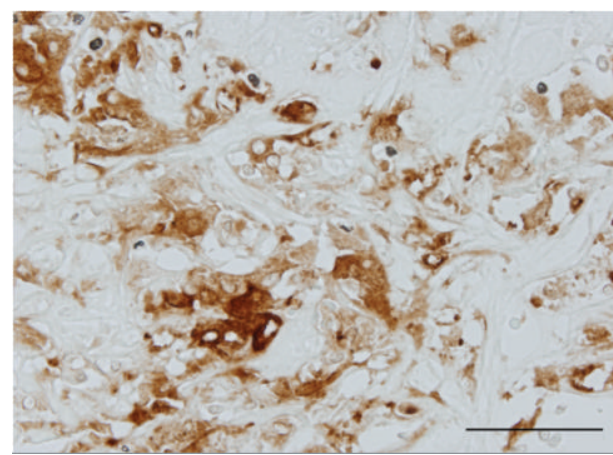

(d) NGCT

FIGURE 1: Immunohistochemistry of amyloid precursor protein (APP) in testicular tissue specimens. (a) Negative control showing negative immunostaining. (b) Normal testicular lesion showing weak staining (intensity score: 1). (c) Seminomatous germ cell tumor lesion showing negative immunostaining (intensity score: 0 ). (d) Nonseminomatous germ cell tumor lesion (embryonal cancer component) showing strong APP immunostaining (intensity score: 3 ). Scale bars, $50 \mu \mathrm{m}$.

immunostaining for APP (Table 1 and Figure 1(c)). Six of 31 a benign testicular lesions (Figure 1(b)) and 1 of 41 SGCTs showed weak immunostaining, with an intensity score of 1+. Four of 41 SGCTs (9.8\%) and 9 of 23 NGCTs (39.1\%) (Table 1) showed an intensity score of $2+$ to $3+$ (Figure 1(d)), and these lesions were considered as showing "positive immunoreactivity (IR)." Positive IR was not seen in SGCT components of the 10 mixed TGCTs.

The rate of positive APP IR was significantly higher in NGCT lesions compared with those in SGCT and in benign testicular lesions $(P=0.0001)$. When compared by pairs, positive APP IR was more frequently observed in NGCT lesions than in SGCT $(P=0.00870)$, although no significant differences were found between SGCT and benign testicular tissues (Table 2). Positive APP IR was not associated with tumor stage or lymph node stage. However, it was associated with elevated $\alpha \mathrm{FP}$ level $(P=0.00870)$ and venous invasion $(P=0.0414)$. Other tumor markers such as LDH and $\beta$ hCG did not show association with positive APP IR.

In all, cancer-specific death occurred in 3.1\% (2/64) of the whole population. There was no significant difference in cancer-specific survival $(P=0.495$; data not shown $)$ and IGCCC ( $P=0.222$, Table 2$)$ between SGCTs and NGCTs. Quantitative RT-PCR analysis was performed to evaluate the
TABLE 1: Immunoreactivity of APP in human testicular specimens.

\begin{tabular}{lccc}
\hline \multirow{2}{*}{$\begin{array}{l}\text { APP intensity } \\
\text { score }\end{array}$} & \multicolumn{3}{c}{ Number of cases (\%) } \\
& Normal testicular tissue & SGCT & NGCT \\
\hline $\mathbf{0}$ & $\mathbf{2 5 ( 8 0 . 6 )}$ & $\mathbf{3 6 ( 8 7 . 8 )}$ & $\mathbf{1 4 ( 6 0 . 9 )}$ \\
$\mathbf{1 +}$ & $\mathbf{6 ( 1 9 . 4 )}$ & $\mathbf{1 ( 0 . 0 2 )}$ & $\mathbf{0 ( 0 )}$ \\
$2+$ & $0(0)$ & $3(0.07)$ & $5(21.7)$ \\
$3+$ & $0(0)$ & $1(0.02)$ & $4(17.4)$ \\
\hline Total & 31 & 41 & 23
\end{tabular}

APP: amyloid precursor protein, SGCT: seminomatous germ cell tumor, NGCT: nonseminomatous germ cell tumor. Intensity score was rated from 0 to $3+$ and defined as 0 : no immunostaining, $1+$ : weak intensity, 2+: moderate intensity, $3+$ : strong intensity. " 0 " and " $1+$ " are defined as "negative immunoreactivity." " $2+$ " and " $3+$ " are defined as "positive immunoreactivity." Numbers in boldface indicate negative immunoreactivity while those in light face indicate positive immunoreactivity.

relative APP mRNA levels in SGCT $(n=15)$ and NGCT $(n=$ 6) tissues. We observed significantly higher levels in NGCT than in SGCT $(P=0.0140$, Figure 2$)$.

\section{Discussion}

APP is ubiquitously expressed in various types of human cells. The extracellular domain of the APP has been suggested 
TABLE 2: Relationships between APP immunoreactivity and clinicopathological characteristics in TGCT patients $(n=64)$.

\begin{tabular}{|c|c|c|c|}
\hline \multirow{2}{*}{ Clinicopathological data } & \multicolumn{3}{|c|}{ APP immunoreactivity } \\
\hline & $\begin{array}{l}\text { Negative } \\
(n=51)\end{array}$ & $\begin{array}{l}\text { Positive } \\
(n=13)\end{array}$ & $P$ value \\
\hline Age (years \pm SD) & $36.5 \pm 10.7$ & $30.0 \pm 15.8$ & 0.182 \\
\hline \multicolumn{4}{|l|}{ Tumor marker } \\
\hline $\mathrm{LDH}$ & & & 0.340 \\
\hline High & 20 & 7 & \\
\hline Normal & 31 & 6 & \\
\hline$\alpha \mathrm{FP}$ & & & 0.00870 \\
\hline High & 14 & 9 & \\
\hline Normal & 37 & 4 & \\
\hline$\beta \mathrm{hCG}$ & & & 0.844 \\
\hline High & 29 & 7 & \\
\hline Normal & 22 & 6 & \\
\hline IGCCC & & & 0.222 \\
\hline Good & 6 & 1 & \\
\hline Intermediate & 2 & 3 & \\
\hline Poor & 0 & 0 & \\
\hline \multicolumn{4}{|l|}{ Stage } \\
\hline T stage & & & 0.0978 \\
\hline $\mathrm{T} 1$ & 36 & 6 & \\
\hline $\mathrm{T} 2-4$ & 15 & 7 & \\
\hline $\mathrm{N}$ stage & & & 0.444 \\
\hline N0 & 43 & 9 & \\
\hline N1-3 & 8 & 3 & \\
\hline Unknown & 0 & 1 & \\
\hline Venous invasion & & & 0.0414 \\
\hline Positive & 7 & 5 & \\
\hline Negative & 44 & 8 & \\
\hline Pathology & & & 0.0001 \\
\hline Benign testicular lesion & 31 & 0 & \\
\hline SGCT & 37 & 4 & \\
\hline NGCT & 14 & 9 & \\
\hline \multicolumn{4}{|l|}{$\begin{array}{l}\text { Compared histological } \\
\text { types }\end{array}$} \\
\hline SGCT versus NGCT & - & - & 0.00870 \\
\hline $\begin{array}{l}\text { SGCT versus benign } \\
\text { testicular lesion }\end{array}$ & - & - & 0.129 \\
\hline $\begin{array}{l}\text { NGCT versus benign } \\
\text { testicular lesion }\end{array}$ & - & - & 0.0002 \\
\hline
\end{tabular}

APP: amyloid precursor protein, TGCT: testicular germ cell tumor, LDH: lactate dehydrogenase, $\alpha \mathrm{FP}$ : alpha fetoprotein, $\beta$ hCG: human chorionic gonadotropin $\beta$ subunit, IGCCC: International Germ Cell Consensus Classification, SGCT: seminomatous germ cell tumor, NGCT: nonseminomatous germ cell tumor.

to be involved in transcellular adhesion [3] and neurite outgrowth $[19,20]$. It may also function as a cell surface receptor $[21,22]$. The intracellular domain of the APP is considered to be involved in cell migration [21, 23], cell

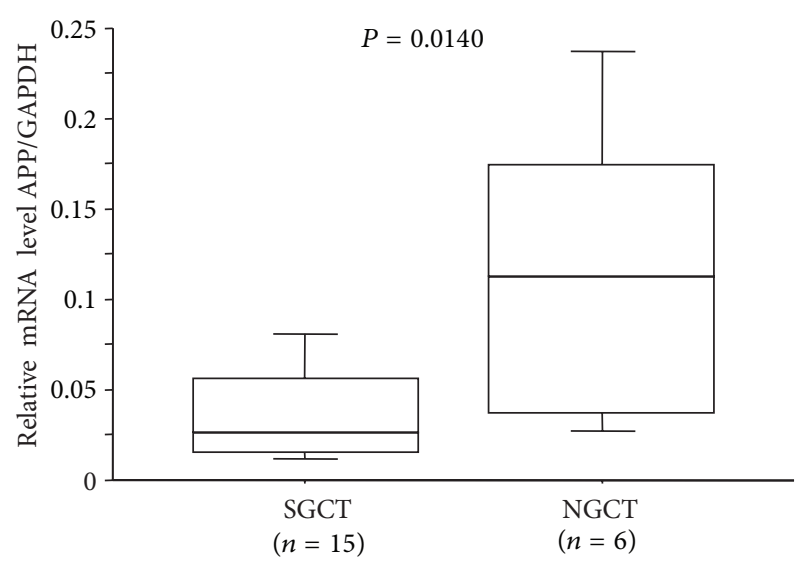

FIgURE 2: Quantitative RT-PCR analysis of amyloid precursor protein (APP) in seminomatous germ cell tumors (SGCTs) and nonseminomatous germ cell tumors (NGCTs). The figures in box and whisker plot show the relative mRNA levels of APP quantified by normalization to GAPDH mRNA levels. Bars, \pm SDs. A statistically significant difference in APP expression was observed between SGCTs and NGCTs $(P=0.0140)$.

signaling [4, 21], and apoptosis [21, 24, 25]. It also activates proliferation of epithelial cells [6]. These lines of evidence suggest that APP is involved in cancer cell proliferation. We have previously reported that APP contributes to androgendependent proliferation of prostate cancer cells and that the rate of cancer-specific survival for patients with APPpositive tumors was lower than that for patients with APPnegative tumors [14]. Another study revealed an APP overexpression in human pancreatic and colon cancer [13]. In the same study, small interfering RNA-mediated knockdown of APP also resulted in decreased cancer cell growth [13]. Involvement of APP expression is also suggested in cancer cells originating from the nasopharynx [8], oral cavity [9], thyroid [10, 11], and colon [12]. In a testicular germ cell tumor (TGCT), a recent study suggested an association of APP expression in transformed human pluripotent stem cells [26]. However, clinical significance of APP expression has not been evaluated. Therefore, we investigated the expression of APP in TGCTs and evaluated its association with clinical characteristics of TGCT.

The present study shows that APP is more strongly expressed in NGCTs than in SGCTs. In terms of APP IR, we found a greater rate of positive cases in NGCTs than in SGCTs (39.1\% versus 9.8\%). APP mRNA levels were higher in NGCTs than in SGCTs. In a study by Venkataramani et al. [26], APP immunostaining was positive in both undifferentiated SGCTs and embryonal cell carcinomas. However, when mRNA levels were compared among cell lines such as TCam-2 (SGCT cell line), NCCIT (mixed cell line of SGCT and NGCT), and NTera-2 (embryonal carcinoma cell line), significantly higher expression levels were observed in the NTera-2 cell line.

Venous invasion, a risk factor for occult metastases of TGCT [27], was also significantly associated with positive APP IR. Together with the result of immunostaining and mRNA analysis, our findings show that APP expression is 
associated with NGCTs and venous invasion, and that APP may be related to a more aggressive carcinogenesis, thus indicating that APP may be a potential prognostic marker of TGCTs.

In the present study, no significant differences were observed in cancer-specific survival between APP-positive and APP-negative cases in a TGCT. Because TGCTs are highly responsive to chemotherapy or radiation therapy, cancer-specific death occurred in only $3.1 \%(2 / 64)$ of the whole study population. In addition, no patient was classified in the poor-risk group in IGCCC in this study. For this reason, we may not have observed significant differences in survival. However, a trend toward an association between APP IR and a higher-risk group in IGCCC were observed. In a study involving a larger patient population, positive APP IR might show a significant association with a worse-survival or a higher-risk group in IGCCC.

The mechanism of APP expression in cancer cells is not fully understood. Growth factors such as EGF and PDGF promote APP cleavage in a Ras-dependent pathway [28]. In nasopharyngeal cancers, APP expression is regulated by epithelial growth factor receptor (EGFR) activation [8]. Because EGFR activation is considered to play an important role in the pathogenesis of many human malignancies [29], APP may be linked to carcinogenesis. Several lines of evidence revealed overexpression and activation of EGFR in NGCT. A study evaluating 24 TGCT cases for EGFR expression showed a strong association between $\beta$ hCGexpressing component of NGCT and EGFR 1 with HER$2 /$ neu coexpression [30]. In this study, expression of the TGF- $\alpha$, a known EGFR ligand, was also found in 36\% of EGFR-positive NGCT cases. Another study showed Her$2 /$ neu overexpression in $24 \%$ of the NGCT cases [31]. EGFR activation in NGCTs and a potential role of EGFR-regulated APP expression in some of the malignancies support the possibility of EGFR-mediated APP expression in NGCTs.

\section{Conclusions}

The current findings show that APP levels are elevated in TGCTs, especially in NGCTs. APP elevation may indicate a more aggressive histological type of TGCTs.

\section{Abbreviations}

APP: Amyloid precursor protein

TGCT: Testicular germ cell tumor

qRT-PCR: Quantitative reverse transcription polymerase chain reaction

SGCT: Seminomatous germ cell tumor

NGCT: Nonseminomatous germ cell tumor

IR: Immunoreactivity

$\alpha \mathrm{FP}: \quad$ Alpha fetoprotein

IGCCC: International Germ Cell Consensus Classification

LDH: $\quad$ Lactate dehydrogenase

$\beta$ hCG: $\quad$ Beta human chorionic gonadotropin

EGFR: Epithelial growth factor receptor.

\section{Conflict of Interests}

The authors declare no conflict of interests.

\section{Acknowledgments}

This study was supported by the Cell Innovation Program and Support Project of Strategic Research Center in Private Universities from the MEXT, grants from the Japan Society for the Promotion of Science, grants-in-aid from the MHLW, and the Program for Promotion of Fundamental Studies in Health Sciences of the NIBIO. The authors thank Dr. Yusuke Sato and Tomoko Yamanaka for their technical assistance.

\section{References}

[1] P. Albers, W. Albrecht, F. Algaba et al., "EAU guidelines on testicular cancer: 2011 update," European Urology, vol. 60, no. 2, pp. 304-319, 2011.

[2] D. J. Selkoe, "Alzheimer's disease: genes, proteins, and therapy," Physiological Reviews, vol. 81, no. 2, pp. 741-766, 2001.

[3] D. Schubert, L.-W. Jin, T. Saitoh, and G. Cole, “The regulation of amyloid $\beta$ protein precursor secretion and its modulatory role in cell adhesion," Neuron, vol. 3, no. 6, pp. 689-694, 1989.

[4] Y. Gao and S. W. Pimplikar, "The $\gamma$-secretase-cleaved Cterminal fragment of amyloid precursor protein mediates signaling to the nucleus," Proceedings of the National Academy of Sciences of the United States of America, vol. 98, no. 26, pp. 14979-14984, 2001.

[5] C. Siemes, T. Quast, E. Klein, T. Bieber, N. M. Hooper, and V. Herzog, "Normalized proliferation of normal and psoriatic keratinocytes by supperssion of $\operatorname{sAPP} \alpha$-release," Journal of Investigative Dermatology, vol. 123, no. 3, pp. 556-563, 2004.

[6] A. Schmitz, R. Tikkanen, G. Kirfel, and V. Herzog, "The biological role of the Alzheimer amyloid precursor protein in epithelial cells," Histochemistry and Cell Biology, vol. 117, no. 2, pp. 171-180, 2002.

[7] T. Saitoh, M. Sundsmo, J. M. Roch et al., "Secreted form of amyloid $\beta$ protein precursor is involved in the growth regulation of fibroblasts," Cell, vol. 58, no. 4, pp. 615-622, 1989.

[8] C. E. Tang, Y. J. Guan, B. Yi et al., "Identification of the amyloid $\beta$-protein precursor and cystatin $\mathrm{C}$ as novel epidermal growth factor receptor regulated secretory proteins in nasopharyngeal carcinoma by proteomics," Journal of Proteome Research, vol. 9, no. 12, pp. 6101-6111, 2010.

[9] S. Y. Ko, S. C. Lin, K. W. Chang et al., "Increased expression of amyloid precursor protein in oral squamous cell carcinoma," International Journal of Cancer, vol. 111, no. 5, pp. 727-732, 2004.

[10] C. U. Pietrzik, J. Hoffmann, K. Stöber et al., "From differentiation to proliferation: the secretory amyloid precursor protein as a local mediator of growth in thyroid epithelial cells," Proceedings of the National Academy of Sciences of the United States of America, vol. 95, no. 4, pp. 1770-1775, 1998.

[11] K. Krause, S. Karger, S. Y. Sheu et al., "Evidence for a role of the amyloid precursor protein in thyroid carcinogenesis," Journal of Endocrinology, vol. 198, no. 2, pp. 291-299, 2008.

[12] J. Y. Meng, H. Kataoka, H. Itoh, and M. Koono, "Amyloid $\beta$ protein precursor is involved in the growth of human colon carcinoma cell in vitro and in vivo," International Journal of Cancer, vol. 92, no. 1, pp. 31-39, 2001. 
[13] V. Venkataramani, C. Rossner, L. Iffland et al., "Histone deacetylase inhibitor valproic acid inhibits cancer cell proliferation via down-regulation of the alzheimer amyloid precursor protein," The Journal of Biological Chemistry, vol. 285, no. 14, pp. 1067810689, 2010.

[14] K. Takayama, S. Tsutsumi, T. Suzuki et al., "Amyloid precursor protein is a primary androgen target gene that promotes prostate cancer growth," Cancer Research, vol. 69, no. 1, pp. 137142, 2009.

[15] G. M. Mead, "International germ cell consensus classification: a prognostic factor- based staging system for metastatic germ cell cancers," Journal of Clinical Oncology, vol. 15, no. 2, pp. 594-603, 1997.

[16] T. Fujimura, S. Takahashi, T. Urano et al., "Estrogen receptorbinding fragment-associated gene 9 expression and its clinical significance in human testicular cancer," International Journal of Urology, vol. 16, no. 3, pp. 329-332, 2009.

[17] D. C. Gilbert, I. Chandler, B. Summersgill et al., "Genomic gain and over expression of CCL2 correlate with vascular invasion in stage I non-seminomatous testicular germ-cell tumours," International Journal of Andrology, vol. 34, pp. 114-121, 2011.

[18] K. Horie-Inoue, K. Takayama, H. U. Bono, Y. Ouchi, Y. Okazaki, and S. Inoue, "Identification of novel steroid target genes through the combination of bioinformatics and functional analysis of hormone response elements," Biochemical and Biophysical Research Communications, vol. 339, no. 1, pp. 99-106, 2006.

[19] E. A. Milward, R. Papadopoulos, S. J. Fuller et al., "The amyloid protein precursor of Alzheimer's disease is a mediator of the effects of nerve growth factor on neurite outgrowth," Neuron, vol. 9, no. 1, pp. 129-137, 1992.

[20] W. Q. Qiu, A. Ferreira, C. Miller, E. H. Koo, and D. J. Selkoe, "Cell-surface $\beta$-amyloid precursor protein stimulates neurite outgrowth of hippocampal neurons in an isoform-dependent manner," Journal of Neuroscience, vol. 15, no. 3, pp. 2157-2167, 1995.

[21] H. Zheng and E. H. Koo, "The amyloid precursor protein: beyond amyloid," Molecular Neurodegeneration, vol. 1, no. 1, article 5, 2006.

[22] A. Ho and T. C. Südhof, "Binding of F-spondin to amyloid$\beta$ precursor protein: a candidate amyloid- $\beta$ precursor protein ligand that modulates amyloid- $\beta$ precursor protein cleavage," Proceedings of the National Academy of Sciences of the United States of America, vol. 101, no. 8, pp. 2548-2553, 2004.

[23] S. L. Sabo, A. F. Ikin, J. D. Buxbaum, and P. Greengard, "The Alzheimer amyloid precursor protein (APP) and FE65, an APP-binding protein, regulate cell movement," Journal of Cell Biology, vol. 153, no. 7, pp. 1403-1414, 2001.

[24] E. Bertrand, E. Brouillet, I. Caillé et al., "A short cytoplasmic domain of the amyloid precursor protein induces apoptosis in vitro and in vivo," Molecular and Cellular Neuroscience, vol. 18, no. 5, pp. 503-511, 2001.

[25] T. Ozaki, Y. Li, H. Kikuchi, T. Tomita, T. Iwatsubo, and A. Nakagawara, "The intracellular domain of the amyloid precursor protein (AICD) enhances the p53-mediated apoptosis," Biochemical and Biophysical Research Communications, vol. 351, no. 1, pp. 57-63, 2006.

[26] V. Venkataramani, K. Thiele, C. L. Behnes et al., "Amyloid precursor protein is a biomarker for transformed human pluripotent stem cells," The American Journal of Pathology, vol. 180, pp. 1636-1652, 2012.
[27] J. W. Moul, W. F. McCarthy, E. B. Fernandez, and I. A. Sesterhenn, "Percentage of embryonal carcinoma and of vascular invasion predicts pathological stage in clinical stage I nonseminomatous testicular cancer," Cancer Research, vol. 54, no. 2, pp. 362-364, 1994.

[28] L. Amigoni, M. Ceriani, F. Belotti, G. Minopoli, and E. Martegani, "Activation of amyloid precursor protein processing by growth factors is dependent on Ras GTPase activity," Neurochemical Research, vol. 36, no. 3, pp. 392-398, 2011.

[29] C. L. Arteaga, "Overview of epidermal growth factor receptor biology and its role as a therapeutic target in human neoplasia," Seminars in Oncology, vol. 29, no. 5, pp. 3-9, 2002.

[30] M. Moroni, S. Veronese, R. Schiavo et al., "Epidermal growth factor receptor expression and activation in nonseminomatous germ cell tumors," Clinical Cancer Research, vol. 7, no. 9, pp. 2770-2775, 2001.

[31] L. Mándoky, L. Géczi, I. Bodrogi et al., "Clinical relevance of HER-2/neu expression in germ-cell testicular tumors," Anticancer Research, vol. 24, no. 4, pp. 2219-2224, 2004. 


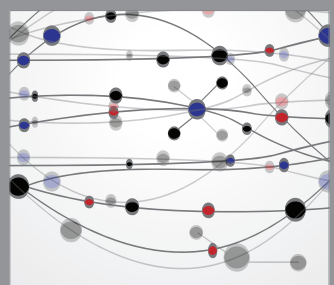

The Scientific World Journal
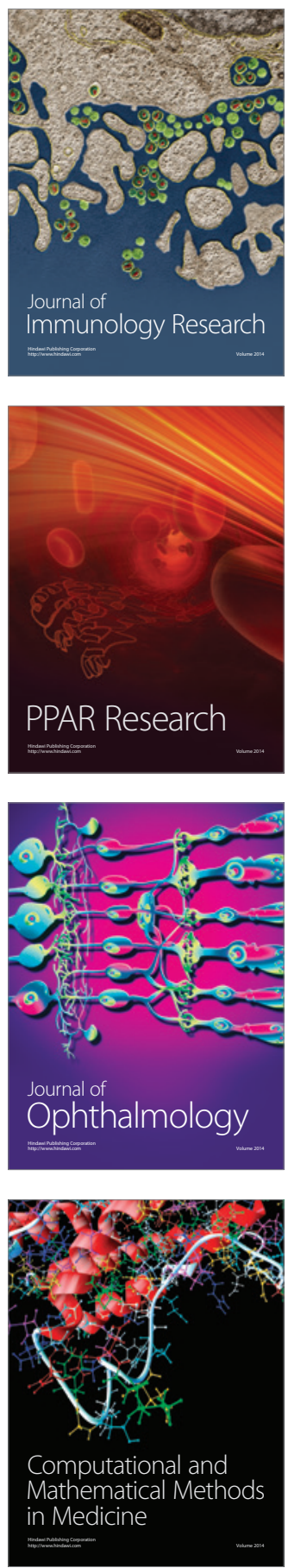

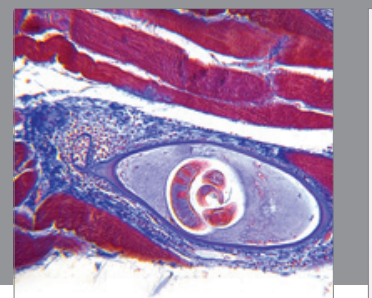

Gastroenterology

Research and Practice
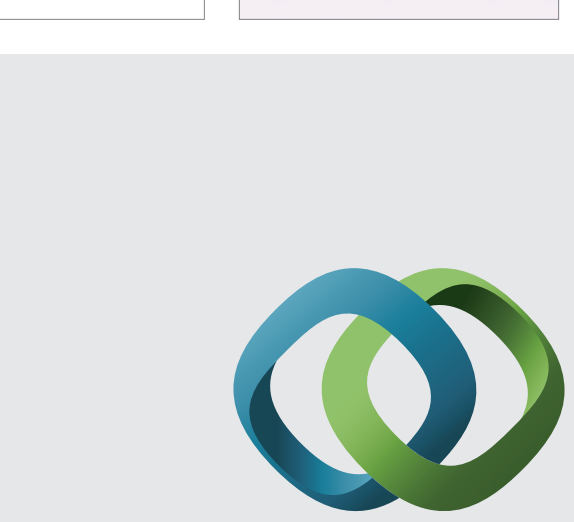

\section{Hindawi}

Submit your manuscripts at

http://www.hindawi.com
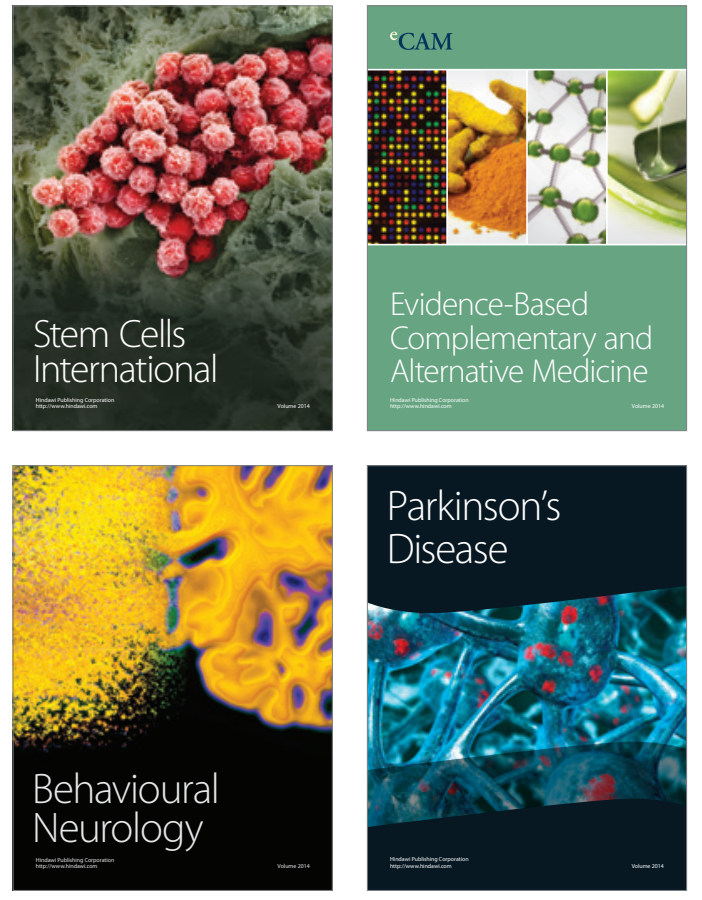
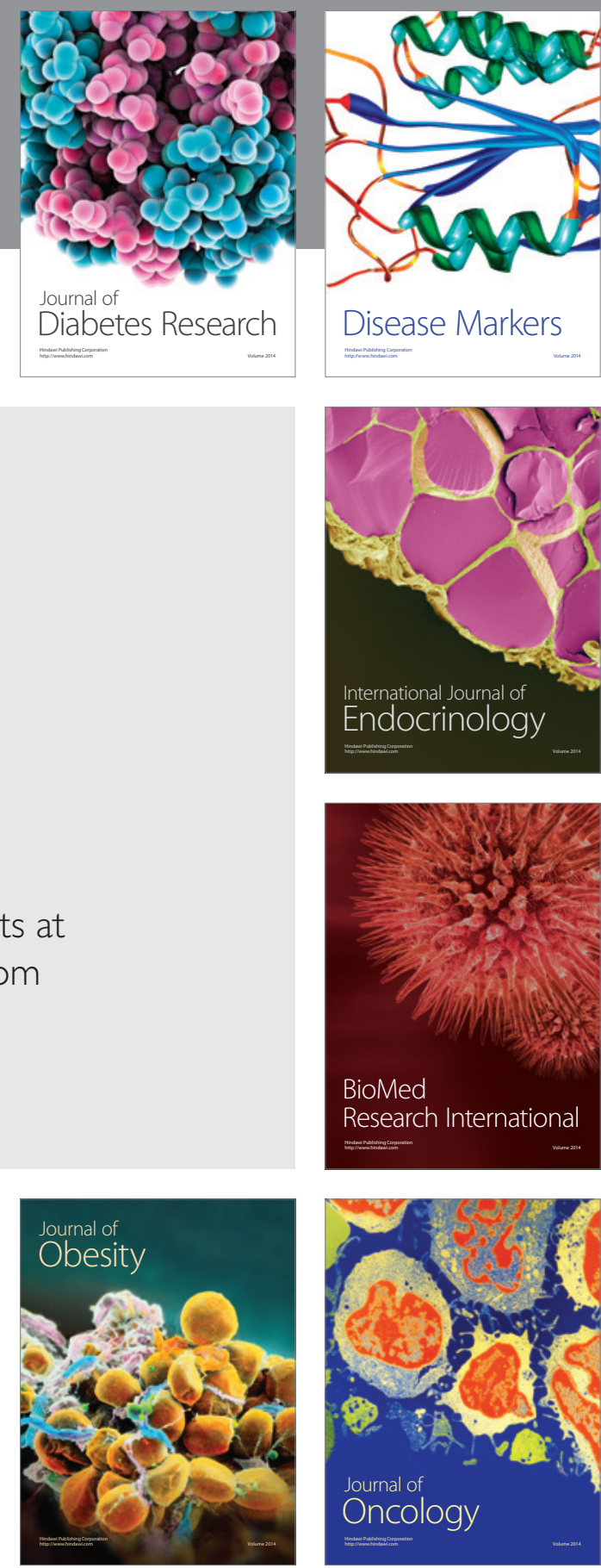

Disease Markers
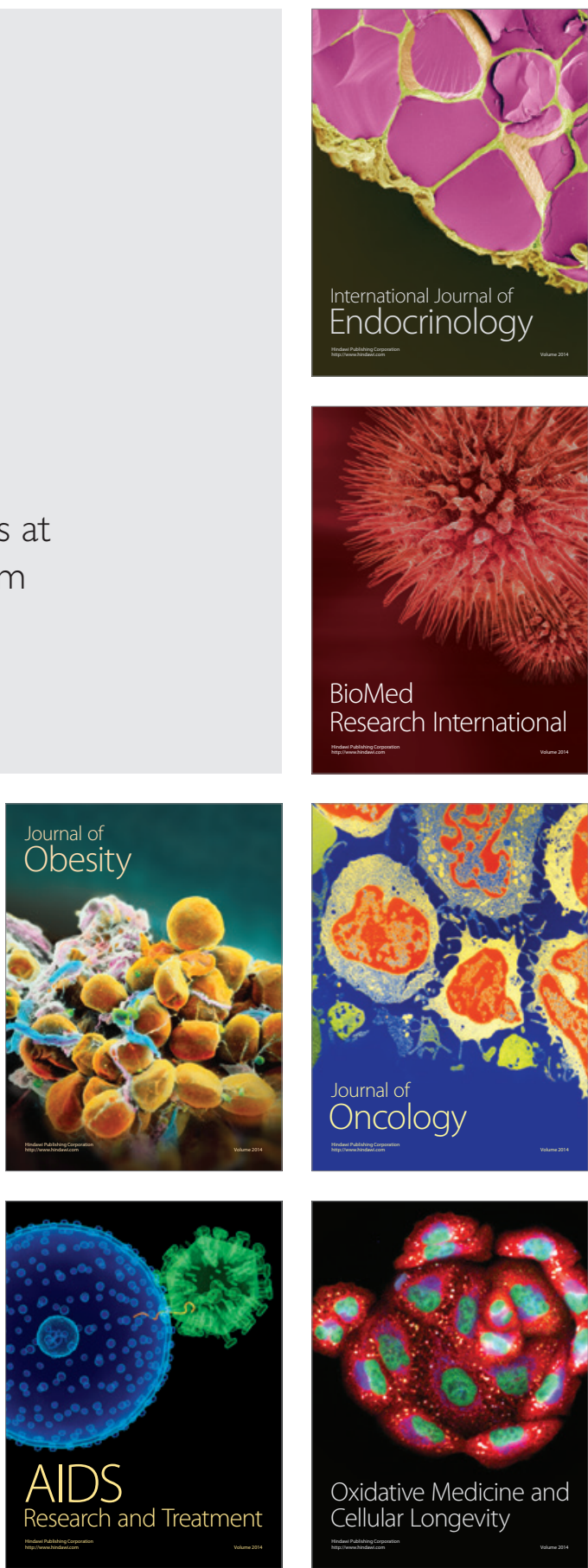